\title{
Laicidade do Estado: dimensões analítico- conceituais e suas estruturas normativas de funcionamento
}

\section{Luis Gustavo Teixeira da Silva*}

\section{Resumo}

O objetivo deste artigo é analisar os diferentes padrões e sentidos do conceito de laicidade do Estado, enquanto princípio político regente das democracias ocidentais, cuja função é assegurar e estabelecer parâmetros de convivência entre convicções morais dissonantes vigentes nas sociedades contemporâneas. Para isso, na primeira seção elaboramos uma definição de laicidade do Estado a partir de seus pressupostos conceituais, históricos e suas dimensões normativas de funcionamento. Na seção seguinte explicitamos as diferenças entre laicidade e secularização, já que questões terminológicas e analíticas tendem a aproximar estes fenômenos e conceitos que, de certo modo, atuam sobre um mesmo plano, todavia são muito distintos. Na última seção realizamos uma análise conceitual das duas principais correntes teóricas, explorando suas peculiaridades e suas aproximações, sobretudo no estabelecimento de um vínculo intrínseco entre democracia e laicidade do Estado.

Palavras-chave: laicidade do Estado, secularização, democracia, religiões, liberdades individuais.

\footnotetext{
*Universidade Federal de Pelotas, Pelotas, RS, Brasil.
} 


\section{Laicity of the State: analytical-conceptual dimensions and their normative structures of operation}

\section{Abstract}

The objective of this article is to present analysis of the different patterns and meanings of the concept of laicity as the guiding political principle of western democracies, aimed at ensuring and establishing parameters of coexistence between dissenting moral convictions in contemporary societies. To that end, a definition of laicity is elaborated based on both its conceptual and historical assumptions and its normative dimensions of operation. Then, the differences between secularism and laicity are made clear, since terminological and analytical matters tend to blend these phenomena and concepts that in a way act on the same sphere, however being distinct. Finally, a conceptual analysis of the two main theoretical strands is proposed, by exploring their peculiarities and approximations, especially in the establishment of an intrinsic link between democracy and the secular State.

Keywords: secular State, secularism, democracy, religions, individual freedoms.

\section{Introdução}

laicidade do Estado, em sua acepção corrente, compreende o
processo de separação institucional e autonomia do Estado com
relação às religiões. Sua aplicação ganha relevo no ocidente a partir do século XIX, especialmente como princípio basilar aos sistemas políticos, em que se acentuou a tendência à independência e à neutralidade do Estado em relação às crenças. Contudo, a noção de laicidade não se restringe a uma norma legal que busca apenas promover a separação institucional entre ditas esferas. Sua função também consiste em reconhecer e garantir de modo equânime a legitimidade das distintas clivagens de pensamento e crenças presentes na sociedade. Sendo assim, seu propósito também consiste em assegurar que a pluralidade de ideias seja preservada, de modo 
a impedir que determinadas concepções de bem se imponham a distintos grupos que não partilham da mesma concepção.

O objetivo deste artigo é analisar os diferentes padrões e sentidos do conceito de laicidade do Estado, enquanto princípio político regente das democracias ocidentais, cuja função é assegurar e estabelecer parâmetros de convivência entre convicções morais dissonantes vigentes nas sociedades contemporâneas. Para isso, na primeira seção elaboramos uma definição de laicidade do Estado a partir de seus pressupostos conceituais, históricos e suas dimensões normativas de funcionamento. Na seção seguinte explicitamos as diferenças entre laicidade e secularização, já que questões terminológicas e analíticas tendem a aproximar estes fenômenos e conceitos que, de certo modo, atuam sobre um mesmo plano, todavia são muito distintos. Na última seção realizamos uma análise conceitual das duas principais correntes teóricas, explorando suas peculiaridades e suas aproximações, sobretudo no estabelecimento de um vínculo intrínseco entre democracia e laicidade do Estado.

\section{Laicidade do Estado: bases conceituais}

A laicidade do Estado é um conceito de natureza normativa, que incorpora e promove um acervo de princípios, cuja função invariavelmente é instituir um modelo de convivência à sociedade, nomeadamente à pluralidade de ideias e modos de vida nela vigentes (Ugarte, 2013; Taylor, 2013). Sua materialização ocorre necessariamente por meio da implementação de dois pilares de sustentação complementares, representados pela dimensão institucional e valorativa, ambos responsáveis por assegurar a liberdade e a igualdade de todas as clivagens de pensamento ou crenças, salvo aquelas de matriz discriminatória (Milot, 2008; Poulat, 2012).

A dimensão institucional se manifesta pela aplicação de dispositivos legais por parte do Estado, com a finalidade primordial de separá-lo das organizações religiosas e obstruir sua interferência nos assuntos públicos. No 
século XX seu espectro de atuação se ampliou às concepções intolerantes à diversidade e privadas de bem (Peña-Ruiz, 2002; Blancarte, 2000).

A dimensão institucional é sistematizada via adoção de quatro normas: 1) neutralidade negativa, que institui a ausência de intervenção do Estado à livre expressão da religiosidade e das convicções dos indivíduos ou grupos, com vistas a garantir o direito à liberdade religiosa; 2) neutralidade positiva, que se caracteriza pela concepção de isonomia do Estado frente às religiões, impedindo-o de outorgar qualquer auxílio, subsídio ou influência, direta ou indireta, em favor das instituições ou de suas organizações, tampouco a uma ou algumas delas; 3 ) liberdade de apostasia, que determina a igual dignidade jurídica do ateísmo; 4) neutralidade das leis civis, que estabelece a separação entre as leis que regem o conjunto da sociedade das normas morais religiosas (Ugarte, 2013).

Sendo assim, o Estado pode ser considerado laico, em sentido pleno, na medida em que assegura devidamente e se compromete com estas normas, transformando-as em direitos fundamentais dos indivíduos e grupos, seja para usufruto ou reivindicação de seu cumprimento (Blancarte, 2008; Maclure; Taylor, 2011). Portanto, a dimensão institucional se torna imprescindível para que a laicidade desempenhe seu papel de regulamentação. É através da aplicação de sua elaboração jurídica que ela se converte em parâmetro de convívio nas sociedades plurais. Entretanto, isso não significa que se reduza a este aspecto - é preciso levar em consideração sua escala de valores, caso contrário há enorme risco de a norma ser nada além de letra morta ou precariamente observada (Poulat, 2012; Peña-Ruiz, 2002).

Nesse sentido, a laicidade também está intimamente relacionada com a promoção de princípios na esfera pública, como a liberdade de consciência e religiosa, autodeterminação individual e coletiva, tolerância e a igualdade (Bovero, 2013). A sedimentação e adesão a estes valores outorgam à laicidade o status de paradigma para um modelo de sociedade desejável do ponto de vista democrático, em que ninguém é privado de (ou obrigado a) crer em algo e adotar um estilo de vida específico (Blancarte, 2004; Taylor, 2013). 
A junção entre a dimensão institucional e a valorativa viabiliza o desenvolvimento da laicidade em duas direções (Ugarte, 2013). No sentido vertical, de cima para baixo, que parte do Estado até a sociedade, no intuito de estabelecer sua neutralidade e normatizar o respeito à diversidade. A outra direção, no sentido horizontal, opera no âmbito das relações sociais. Esta característica se concretiza, em maior ou menor medida, por meio da adesão e internalização de seus princípios, convertendo-a em convenção, melhor dizendo, regra consuetudinária (Poulat, 2012; Peña-Ruiz, 2010).

É precisamente com base nesse enquadramento que se situa a essencial relevância da laicidade na construção do Estado moderno e na elaboração das constituições liberais a partir dos séculos XVIII e XIX, em países como França e Estados Unidos. Tendo em vista que, por um lado, a laicidade proporciona os alicerces para que o Estado seja inteiramente autônomo no sentido legal, por outro, é uma das fontes de seus princípios de orientação, constituídos pelas noções de igualdade, liberdade e tolerância. Isso não significa dizer que Estado laico seja (ou deva ser) um ente hostil ou alheio às demais concepções presentes na sociedade, pelo contrário, sua obrigação é estar aberto a todas elas para estabelecer canais profundos de interlocução (Maclure; Taylor, 2011). A diferença é entender que há limite em sua permeabilidade, pois para que sua atuação seja legítima, é necessário prescindir de formulações éticas e morais remanescentes de matrizes religiosas ou seculares de natureza sectária. Sua razão de existir reside justamente em não incorporar nenhuma premissa ou cultura específica, para que torne possível a existência de todas elas.

Nesses termos, a laicidade pareceria um projeto político relativamente simples de implementação, afinal, sua atribuição nada mais é que garantir a administração do Estado por meio de perspectivas seculares comuns a todos, e estabelecer o respeito mútuo entre pessoas portadoras de diferentes convicções, sem que para isso seja necessário renunciar à livre manifestação delas. O caráter intrinsecamente conflitivo é adquirido quando instituída em lugares onde há prévia existência de religiões hegemônicas, com significativa influência na construção do Estado e na definição dos valores públicos 
(Milot, 2010). A construção do Estado laico e sua relação com a Igreja Católica é identificada como o principal exemplo desse processo de tensão.

Historicamente, a Igreja se mobilizou intensamente para combater a efetivação da laicidade e de seus ideais, sobretudo na Europa e América Latina (Seleme, 2013). Esta resistência se consolidou ao se tornar peça central na agenda de reformas eclesiais promovidas pelo Papa Pio XI (19221939), que também incluíam a moralização dos costumes. O referido pontífice foi responsável por cunhar os termos laicismo e laicista que, em sua perspectiva, designavam a utilização do aparato estatal de forma intolerante e opressiva à Igreja, para promover a neutralidade do Estado e as liberdades laicas. Dessa compreensão resulta sua defesa do modelo de laicidade "não laicista", o qual seria mais aberto e compreensível à relevância das instituições religiosas à sociedade e aos governos (Bovero, 2013). Essa distinção se cristalizou no discurso contemporâneo das diferentes correntes cristãs (Blancarte, 2008).

Os padrões de relação estabelecidos entre a política e a Igreja Católica (e demais instituições cristãs) contribuem para explicar os diferentes desenhos de organização da laicidade na Europa e América Latina. Por exemplo, o modelo adotado pode ser mais maleável, absorvendo em maior ou menor medida a ingerência religiosa, sob o risco de o Estado laico abandonar sua função. De outro modo, o modelo pode ser decorrente de um processo de ruptura, resultando na clara delimitação das fronteiras, contudo envolvendo constantemente conflitos e riscos à liberdade religiosa. Para identificar estes modelos, Micheline Milot (2009) elaborou cinco tipos ideais com base nas experiências mais acentuadas historicamente e que, de alguma forma, são verificáveis nas sociedades atuais. Estes modelos realçam, cada um ao seu modo, algum dos princípios da laicidade.

A laicidade separatista se caracteriza pela ênfase na divisão quase tangível entre os espaços da vida privada e a esfera pública. Esta concepção tornou possível construir o governo civil de modo autônomo e sob parâmetros seculares em sociedades marcadamente religiosas e com expressivo poder das Igrejas. As formulações mais notáveis deste arranjo se encontram 
nas reflexões dos filósofos ingleses do século XVIII, principalmente em John Locke, cuja obra Cartas sobre a tolerância apontou a imprescindível necessidade de distinguir os domínios concernentes ao Estado e aqueles pertencentes à religião. Esta concepção teve relevante influência na elaboração da $1^{\circ}$ Emenda da Constituição dos Estados Unidos e na Lei de Separação entre Estado e Igreja na França em 1905.

A laicidade anticlerical ou antirreligiosa se define nas situações em que o Estado e setores da sociedade marginalizam as instituições religiosas e quaisquer intenções destas em intervir no debate público com base em suas crenças. As críticas de Voltaire ao catolicismo compõem a principal base de construção deste modelo. Para os movimentos anticlericais da França e do Uruguai no século XIX, influenciados pelas ideias iluministas e liberais, a religião era sinônimo de atraso e obscurantismo. Esta concepção teve maior adesão nos países de maioria católica do que em países protestantes, e tinha por orientação deslegitimar a hegemonia do poder clerical nos assuntos públicos.

A laicidade de tipo autoritário é verificada nos casos em que o Estado se torna abruptamente independente dos poderes eclesiásticos. Este modelo, em algumas circunstâncias, se aproxima da intolerância, pois o Estado age de modo arbitrário para eliminar qualquer nicho de influência das instituições religiosas sobre a sociedade. Os regimes totalitários do século XX, como a União Soviética, se notabilizaram por implementar este modelo, ao estipular o Estado como ateu e proibir atividades religiosas.

O quarto, intitulado fé cívica, se caracteriza pela incorporação da laicidade no arranjo de valores que estruturam a sociedade política. Jean Jacques Rousseau foi o responsável por desenvolver o raciocínio que compõe o modelo. Embora não estivesse fazendo referência à laicidade, destacou no livro Carta a Voltaire, de 1756, a emergência de que cada Estado fosse portador de um código moral objeto de devoção civil. Por exemplo, o Uruguai é um caso paradigmático na adoção deste tipo de modelo, tendo em vista que neste país se construiu ao longo dos anos uma espécie de 
"religião civil", em que a laicidade e as instituições do Estado são vistas como sagradas (Guigou, 2011; Silva, 2018a).

Por último, a laicidade por reconhecimento se caracteriza quando o Estado reconhece a autonomia moral de cada cidadão para decidir seu plano de vida, assim como o direito inalienável de expressar livremente sua religiosidade. Este modelo tem adquirido notoriedade nas discussões contemporâneas, sobretudo com relação aos desafios engendrados pela diversidade moral. Seus expoentes teóricos são Charles Taylor e a própria Micheline Milot, como veremos com mais detalhes adiante.

Os modelos de laicidade são construções sociais conjugadas a partir de fatores referentes às dinâmicas e desafios enfrentados nos contextos nacionais. As aproximações destes arquétipos podem ser construídas, coexistirem e/ ou se redefinirem de acordo com as disputas e processos sociais. A tensão entre as instituições políticas e a Igreja Católica é frequentemente o principal vetor que impulsiona maiores transformações em sua conformação.

Conforme argumenta Émile Poulat (2012), a modificação do status público da Igreja e das perspectivas cristãs transforma a laicidade em projeto complexo, adquirindo contornos, de acordo com o caso, semelhantes a uma "revolução cultural". Paradoxalmente, a história do surgimento da laicidade do Estado está profundamente ligada à contribuição de movimentos e instituições cristãs, seja em seu marco conceitual ou no desenvolvimento de seu projeto político. Seu protótipo teórico rudimentar foi elaborado no século V (494 E.C.) pelo Papa Gelásio I, conhecido como a teoria das "Duas Espadas". Em epístola enviada ao Imperador bizantino Anastásio, o pontífice anunciou seu desejo de separar o poder temporal pertencente ao Imperador (potestas) do poder espiritual da Igreja (auctoritas), utilizando como metáfora a impossibilidade de segurar na mesma mão duas espadas. O propósito era proteger a Igreja, ao torná-la plenamente independente das vicissitudes do mundo político da época (Galeana, 2013). Ao longo dos séculos, a teoria gelasiana foi continuamente recuperada (comumente com o objetivo oposto aos do pontífice supracitado), nas incipientes tentativas de implantação de projetos com aspecto similar à laicidade, tais como, a 
defesa da autonomia da política frente às pretensões de supremacia da Igreja, realizada no século XIII pelos renascentistas Dante Alighieri, Marsílio de Pádua e Giovanni de Paris (Bovero, 2013).

A laicidade do Estado como conhecemos foi construída entre os séculos XVIII e XIX na Europa, a partir das reflexões de filósofos, grupos iluministas e liberais. Nesta circunstância, o modelo de laicidade agregou, a partir de matrizes rudimentares, a separação institucional das esferas e incorporou potencialmente um ideal de civilização, forjado em uma arte de convivência harmônica, com base na justa paridade entre os diferentes costumes e crenças (Poulat, 2012; Milot, 2008). Além disso, outras condições culturais foram favoráveis ao surgimento e expressiva difusão da laicidade na Europa - por exemplo, a reforma protestante foi determinante em sua consolidação. Isto porque a expansão do protestantismo provocou uma ruptura na unidade do cristianismo, em virtude da crítica em torno dos princípios e organização do catolicismo, o que resultou nas guerras religiosas ocorridas entre os séculos XVI e XVII. A intensiva mobilização das Igrejas protestantes à sua execução (já com notável poder em países importantes do continente europeu) representou o apoio a um arranjo social orientado a administrar a pluralidade de crenças, garantindo certa liberdade de culto e proteção diante de possíveis intervenções da Igreja Católica (Ugarte, 2013).

A partir dessas considerações, podemos constatar que o sentido atribuído pelas instituições religiosas à laicidade do Estado flutua, dependendo de sua posição na sociedade. Por exemplo, a Igreja Católica empreendeu sua vigorosa defesa nos países do leste europeu, em que era minoritária e permanentemente alvo do regime soviético. As igrejas protestantes e pentecostais na América Latina, por outro lado, mobilizaram-se a favor da implementação nas primeiras décadas do século XX, por conta da perseguição católica, mas atualmente encontram-se no centro das investidas para enfraquecer seus propósitos. Assim, religiões majoritárias tendem a percebê-la como ferramenta de ação política intolerante e opressiva; já as minoritárias, como a própria salvaguarda de sua existência. Para além da prosaica assertiva de que determinadas religiões são mais inclinadas que 
outras a aceitá-la, a história demonstra inúmeros casos de mudança nos papéis conforme a correlação de forças em que estão inseridas.

\section{Laicidade do Estado e secularização: distinções terminológicas e analíticas}

A etimologia da palavra laicidade é derivada do adjetivo latino laicus (leigo, desconhecedor) que, por sua vez, é proveniente do termo grego laikós - ambos designam o indivíduo sem distinções, pertencente ao povo (laós). A Igreja Católica foi responsável por popularizar o léxico de expressões procedentes de laicus, com o intuito de definir o que era exterior à jurisdição eclesial, isto é, as pessoas e associações que não formavam parte do clero ou de suas iniciativas, respectivamente. A palavra secular, originária da sentença latina saeculum (deste século/mundo), também foi (e é) igualmente empregada pelos católicos com a finalidade de designar aquilo que era de natureza terrena/mundana (Galeana, 2013). Como podemos notar, estas expressões estavam inicialmente restritas ao ambiente cristão, serviam para distinguir internamente e circunscrever a comunidade. No entanto, desde o século XIX, a conotação destes vocábulos e suas variações extrapolaram o âmbito das igrejas, pois passaram a ser adotadas para denominar ações distintas ou até em oposição ao universo religioso.

Nos países de língua latina, os usos das derivações do radical laicus são mais frequentes. Já entre anglófonos e germânicos as variações de secular são preponderantes. No âmbito cristão, os termos são empregados geralmente com sentido equivalente - as complicações surgem quanto a sua aplicação para descrever reformas sociais e políticas. Os idiomas latinos oferecem a utilização de laicidade e secularização para retratar esses dois conceitos e fenômenos. Já o inglês e o alemão, para estes mesmos propósitos, contam apenas com as inflexões de secular, como secularism e säkularität, respectivamente $^{1}$ (Blancarte, 2008; 2004; Milot, 2009).

\footnotetext{
${ }^{1}$ Isto se reproduz na literatura acadêmica. Apenas recentemente alguns textos em inglês têm adotado laicity, porém ainda é majoritário o uso de secularization/secularism para descrever a laicidade do Estado.
} 
Este impasse nas nomenclaturas pode ser atribuído a questões históricas. Isto porque, nos países latinos, a construção do Estado como entidade independente à religião exigiu, em boa parte dos casos, ruptura profunda com o absoluto predomínio da Igreja Católica. Por outro lado, devido à ausência de um poder eclesiástico dessa envergadura nos países anglo-saxônicos, de maioria protestante, a laicidade do Estado foi implementada como processo análogo à secularização dos espaços públicos, como cemitérios e hospitais, logo, sem maiores disputas e prescindindo de sentença particular (Milot, 2008; Blancarte, 2008).

Essas aproximações entre laicidade e secularização são menos problemáticas quando restritas aos termos e variações idiomáticas. O impasse consiste quando indistinções são transferidas à compreensão dos conceitos e fenômenos, pois são muito diferentes entre si, apesar de compartilharem alguns aspectos e, até certo ponto, atuarem sob um mesmo espectro. Como vimos, a laicidade apresenta uma natureza normativa, está vinculada à neutralidade do Estado, à ausência de condicionamentos de caráter religioso, além da incorporação e promoção, na esfera pública, de valores como liberdade de consciência e crença. Por seu turno, a secularização indica tendências empiricamente observáveis relativas à perda de relevância da religião e de seus pressupostos nas estruturas sociais, bem como na orientação do comportamento individual e dos juízos morais (Casanova, 1994).

A secularização é um processo oriundo dos esforços, teóricos e práticos, pela diferenciação das esferas sociais, isto é, a política, cultura, economia e a ciência operando de modo emancipado à religião, de acordo com seus próprios critérios e lógicas de funcionamento (Tschannen, 1991; Berger; Zijderveld, 2012). Este fenômeno está intrinsecamente relacionado ao que se convencionou chamar de modernidade, caracterizada por promover valores e uma visão de mundo sustentada pela razão, mas também profana, antropocêntrica e plural (Zepeda, 2010; Mariano, 2016).

É possível associar o ápice da secularização ao Iluminismo, momento em que se tornou matéria de acentuada atenção no plano filosófico e projeto 
político de Estado. Entretanto suas origens podem ser atribuídas a períodos históricos que remontam ao início da Era Moderna (Casanova, 1994). Por exemplo, o movimento renascentista emergiu mediante a elaboração de paradigmas artísticos, sociais e culturais autônomos e adversos àqueles determinados pela Igreja na Idade Média.

A partir dessas considerações iniciais, podemos destacar quatro características conexas de desenvolvimento da secularização. A primeira delas é sua expansão gradativa, pois acontecimentos ao longo dos séculos contribuíram para sua edificação. Em seguida, sua desuniformidade, já que a autonomia das diferentes esferas não ocorreu simultaneamente e pelas mesmas razões. Em terceiro, assinalar seu aspecto "informal", ou seja, sua construção foi resultado de processos sociais, comumente sem a existência de prescrições oficiais com pontos de partida ou sistema comum de execução. Por essas razões a secularização se caracteriza por não haver produzido excessivos conflitos ou tensões (Milot, 2009). Nas circunstâncias em que estes ocorreram, foram motivados por embates pontuais entre a Igreja e alguns grupos. Por último, convém assinalar que tal fenômeno se desenvolveu com estas bases eminentemente no contexto europeu (Zepeda, 2010; Berger; Zijderveld, 2012).

Duas correntes teóricas buscam analisar a secularização e seus desdobramentos no mundo contemporâneo. A chamada tese rígida é a mais conhecida, sobretudo por ser a mais controversa, dado que o núcleo central desta concepção está formulado sob a premissa de que o predomínio da razão seria capaz de promover mudanças socioculturais profundas, a ponto de provocar a irreversível marginalização da religião à esfera privada, ou até seu desaparecimento (Casanova, 2012). Essa hipótese se desenvolveu com base no prognóstico de que a diferenciação institucional das esferas sociais seria orientada exclusivamente pelo conhecimento técnico-científico. Neste cenário projetado às sociedades modernas, a legitimidade e a capacidade de integração da religião seriam suplantadas pela racionalidade e validade científica das ideias difundidas na esfera pública (Blancarte, 2012; 2015; Berger; Zijderveld, 2012; Mariano, 2016). 
De acordo com este ponto de vista, a secularização representaria um dos processos centrais de transição das sociedades tradicionais, rurais e atrasadas para sociedades complexas, urbanas e avançadas. Essa tese é derivada do arquétipo teórico Iluminista, sustentada sob uma perspectiva histórica unilinear, etapista e evolutiva. Esta forma de compreensão foi superada no contexto atual. Com relação à tese rígida, além do suporte conceitual, sua perda de credibilidade foi agravada pela evidente incapacidade de explicar a desprivatização da religião e seu vertiginoso ressurgimento no último quarto do século XX (Casanova, 2012; Zepeda, 2010; Kepel, 1992).

A tese flexível emerge no cenário acadêmico com o intuito de reintroduzir sob novos ângulos a discussão sobre a secularização. A crítica à abordagem rígida se concentra em aspectos como: a normatividade, devido à transformação de um paradigma analítico em programa político a ser atingido; a transposição mecânica do conceito a países com trajetórias e formações dessemelhantes em comparação aos europeus; e, claro, as conjecturas causais e escatológicas (Casanova; 1994; 2012; Tschannen, 1991; Berger; Zijderveld, 2012).

O eixo central da tese flexível é a preservação da relevância da noção de secularização no mundo contemporâneo, como fenômeno social e perspectiva analítica. Isto posto, com base no fato de que o ressurgimento da religião não provocou seu retorno ao centro da vida social, pelo menos nos países ocidentais - afinal, esferas como a economia, ciência, cultura e até a política conservam substancialmente suas especificidades - o conceito se organiza em torno de três unidades: racionalização, mundanização (ou profanização) e diferenciação, sendo este último considerado seu núcleo primordial (Tschannen, 1991; Casanova, 1994).

Essa abordagem inova ao compreender que religiosidade e secularização não são incompatíveis, esses processos podem coexistir, mesmo que produzindo tensões entre algumas esferas (Blancarte, 2012). Além disso, outro fator singular diz respeito à percepção de que os novos movimentos recristianizadores, apesar de seu profundo conservadorismo moral, construíram sua liturgia por meio do reconhecimento da legitimidade de 
cada esfera da sociedade, em muitos casos se adaptando ou incorporando premissas provenientes delas (Kepel, 1992). Os dados demonstram que a oposição de muitas lideranças e associações religiosas aos direitos LGBTT e à interrupção voluntária da gravidez, em certos casos, está razoavelmente embasada em pressupostos científicos, ainda que geralmente em premissas exóticas da reflexão acadêmica. De fato, é preciso ser cético de que isso se refira a uma defesa genuína do conhecimento científico; todavia representa certa aproximação e reconhecimento da legitimidade de um campo anteriormente "demonizado" pelas religiões. Assim, a secularização é entendida como processo dinâmico, cercado por atritos e pela fluidez das fronteiras entre as esferas que compõem seu sistema (Zepeda, 2010).

Para deixar mais claro, elaboramos esquemas para explicar graficamente o que foi escrito até aqui a respeito da secularização. Na Figura 1, apresentamos um esboço da tese rígida da secularização, onde há acentuada diferenciação de cada esfera social; já a religião perde sua relevância e está à margem. Na Figura 2, consta o protótipo da tese flexível, com todas as esferas dispostas e com pontos de intersecção, maiores ou menores, entre elas.

Figura 1: Tese rígida da secularização

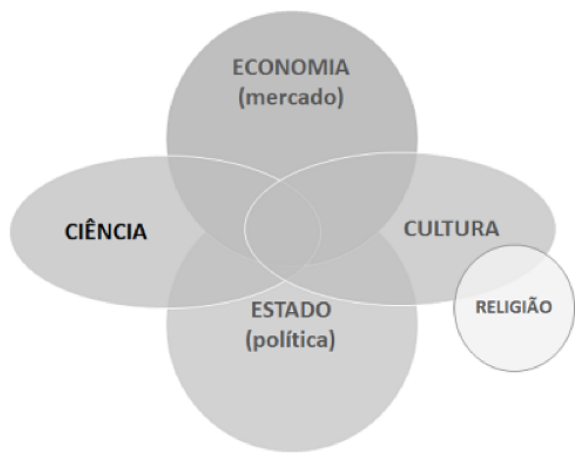

Fonte: Elaboração própria. 
Figura 2: Tese flexível da secularização

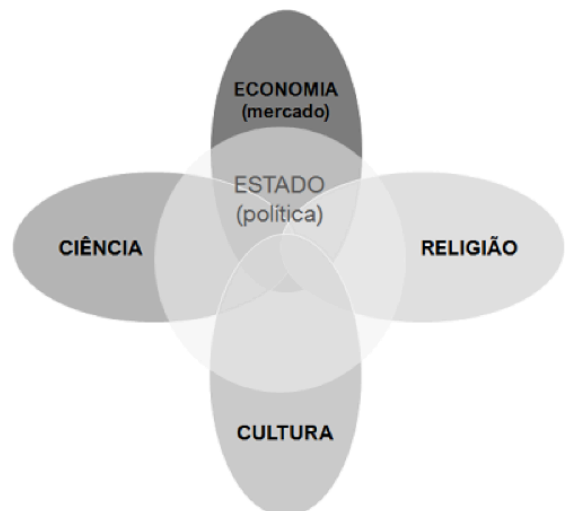

Fonte: Elaboração própria, inspirado no esquema apresentado por Blancarte (2015) ${ }^{2}$.

No contexto geral, a laicidade se diferencia da secularização por se configurar como instrumento engendrado por uma esfera portadora do poder de regulação sobre as outras, o Estado/política, cujo propósito é delimitar o perímetro de atuação das convicções e organizações religiosas, neutralizando sua ingerência sobre o próprio Estado e nos domínios sob sua jurisdição. Outros três pontos específicos realçam essa diferença. Em primeiro lugar, a laicidade é instituída via norma legal, a qual tem por objetivo tornar o Estado/política independentes de qualquer confissão. Em segundo, apresenta aspecto disruptivo, pois a partir de seu ato fundacional nenhuma concepção ou entidade religiosa deverá, em tese, orientar as ações das instituições políticas e jurídicas. Consequentemente, isso remete à sua dimensão conflitiva por espaços, sobretudo entre o Estado e religiões majoritárias.

Na figura 3, apresentamos novamente um esquema gráfico para demonstrar o locus de operacionalização da laicidade no conjunto das

${ }^{2}$ Realizamos mudanças significativas em relação ao esquema de Blancarte (2015). Em nosso ponto de vista há pontos de intersecção entre as esferas da ciência e cultura; cultura e economia; ciência e religião (menor entre todos). No modelo de Roberto Blancarte estas esferas estão isoladas e sem qualquer contato. 
esferas sociais esboçado pela tese flexível da secularização. É possível distinguir três tonalidades na área demarcada, representando os diferentes papéis que a laicidade deve desempenhar.

Figura 3: Laicidade do Estado

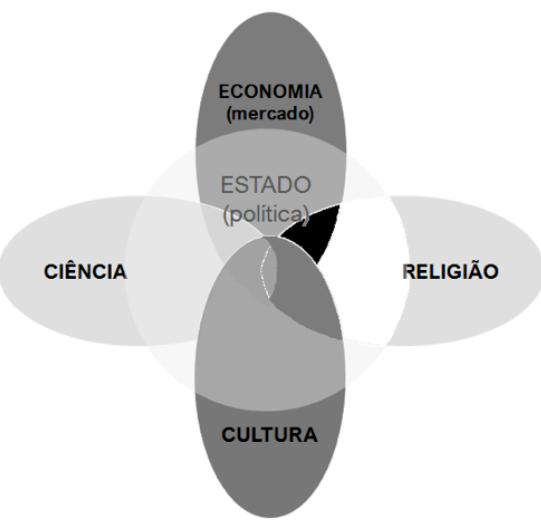

Fonte: Elaboração própria, inspirado no modelo de Blancarte (2015) ${ }^{3}$.

A parte maior (em branco) representa a peculiar característica de separação institucional entre Estado/política e religião, mas também a liberdade religiosa, princípio legal que regula a esfera da religião para assegurar a livre manifestação das distintas crenças, bem como proteção às instituições religiosas de intervenções arbitrárias do Estado/política. Na parte em cinza escuro, intersecção entre Estado/política, cultura e religião, está presente seu papel de garantir a liberdade de consciência, ao impedir que valores religiosos (ou de outra natureza) adquiram legitimidade e sejam impostos ao conjunto da sociedade. Sendo assim, estão inseridos também neste espaço os arranjos sociais e ideias que propagam uma concepção de bem discriminatória e segregacionista, tais como os nacionalismos, a

${ }^{3}$ Além das mudanças informadas na nota anterior, nesta figura diferenciamos em sombreados cada locus de atuação da laicidade, de acordo com as esferas sociais e suas respectivas intersecções. 
xenofobia e ideologias intolerantes à diversidade étnica, social, sexual e religiosa.

Na parte em preto, intersecção entre Estado/política, economia, religião e cultura, encontram-se mais nitidamente os novos desafios da laicidade, notadamente a regulamentação da influência do poder econômico sobre questões públicas, seja oriundo das religiões, como o controle sobre sua atuação na mídia, ou de perspectivas seculares, tais como a ideia de primazia e preservação dos interesses do mercado em relação aos interesses governamentais, sociais e comunitários. Pablo Iglesias (2009) apresenta esta ideia singular, a partir do entendimento de que a concepção neoliberal do Estado, mediante o respeito às leis do mercado, converteu-se nos últimos anos em um dos principais fundamentos de organização da sociedade e da administração pública. Considerado um novo clericalismo, este dogmatismo econômico afeta diretamente os pilares de funcionamento da laicidade, uma vez que o desmantelamento do Estado limita sua capacidade de atuar de acordo com o interesse geral. Entendemos ser possível acrescentar outro aspecto à sua reflexão, isto é, o neoliberalismo também pode se constituir em risco à laicidade nas situações em que atenta contra a diversidade social, uma vez que suas políticas buscam impor um modo de pensamento e um estilo de vida específico a todo conjunto da sociedade, alicerçado pelo empreendedorismo via livre iniciativa comercial.

O processo de secularização contribuiu preponderantemente para autonomia do Estado e da política. A laicidade do Estado, por sua vez, é a ferramenta que aprofunda a emancipação dessa esfera. Apesar da estreita relação entre os fenômenos, eles não representam a mesma coisa. Roberto Blancarte $(2012 ;$ 2015) registra disjunções em seus respectivos desenvolvimentos. Por exemplo, há países que avançaram na secularização, todavia convivem com uma débil aplicação da laicidade, como Brasil e Israel (Mariano, 2011; Silva, 2017). Os países soviéticos, e outros inspirados no regime, registraram um cenário inverso, em virtude da autoafirmação do Estado como ateu. Já França e Uruguai apresentam profundo desenvolvimento de ambos os processos (Silva, 2018b). Sendo assim, podemos notar que estes 
fenômenos e a relação entre eles são matérias complexas, heterogêneas e dinâmicas, a qual pode implicar em recuos e avanços, dependendo das forças políticas e sociais em disputa.

\section{As construções teóricas sobre a laicidade do Estado}

A discussão teórica sobre o conceito de laicidade do Estado se organiza em torno de dois paradigmas, conhecidos como laicidade aberta e fechada. Ambos têm papel relevante na reflexão sobre o fenômeno no contexto recente, no entanto apresentam uma série de tensões, sobretudo quanto à função do Estado e da prática religiosa no espaço público, que são examinados no interior do próprio marco conceitual e na oposição entre as abordagens.

O paradigma aberto propõe a definição do conceito de laicidade por meio da análise acerca da função do Estado e sua relação com as crenças (Maclure; Taylor; 2011). Este enquadramento atribuiu à laicidade papel significativo no conjunto de reflexões que compõem as noções de comunitarismo e multiculturalismo, como a crítica à homogeneização cultural pela integração identitária a princípios universais (Taylor, 2007; Kymlicka, 1995).

A reflexão parte da enunciação corrente de que o Estado deve estar separado das organizações confessionais e o poder político neutro em relação às crenças (Maclure; Taylor, 2011). Esta organização das esferas é considerada fundamento das democracias liberais, regidas pela noção de igualdade entre as pessoas. Por isso, as instituições públicas precisam ser imparciais quanto às visões de mundo, sejam elas provenientes de matrizes religiosas ou seculares com inflexão sectária (Taylor, 2007, 2012; 2013).

Agora, mais especificamente no paradigma aberto, a missão do Estado laico se concentra primordialmente em proteger a liberdade de consciência e assegurar a igualdade moral entre os múltiplos sistemas de valores vigentes na sociedade. Portanto, sua função consiste em favorecer o desenvolvimento da autonomia dos indivíduos, para que de modo soberano possam decidir 
seu plano de vida conforme suas convicções, com pleno respeito ao direito dos demais em fazer o mesmo (Nussbaum, 2010). Sendo assim, estes princípios constituem as bases para um modo de coexistência respaldado pela cooperação, reciprocidade e tolerância à diferença, cujo possível resultado é a estabilidade política em sociedades plurais e democráticas (Taylor 2012; Kymlicka, 1995; Walzer, 1999).

Nesta perspectiva, a laicidade se constitui como princípio político e jurídico que opera para assegurar a diversidade moral e religiosa, composta por crenças teístas, ateístas e filosofias seculares, ao invés de promover, como propõe a ideia de laicidade fechada, seu apagamento, marginalização e/ ou suplantação por outra ordem de normas de regimento da composição social (Kymlicka, 1995).

A dimensão institucional da laicidade, estruturada pela separação e neutralidade do Estado, se constitui no modelo aberto como recurso que permite promover e administrar de forma equânime o pluralismo moral. Estes instrumentos devem ser as principais referências de orientação das ações do Estado, no sentido de impedir a hierarquização entre as concepções de bem mediante a vinculação a alguma(s) delas, assim como instituir a ausência de privilégios ou intervenção à livre expressão de opiniões e/ou da fé (Taylor; 2007; 2012; 2013; Walzer, 1999).

A laicidade aberta é compreendida como concepção mais maleável à manifestação e afluência da religião no espaço público, pontos que são objeto de extensas críticas, inclusive no próprio campo do multiculturalismo, em que é possível observar ângulos conceituais dissonantes. Nesse sentido, convém ressaltar o pensamento de Micheline Milot, atualmente uma das mais proeminentes intelectuais do tema. Seu ponto de divergência basicamente conflui à acepção de que a história não oferece um quadro minimamente animador acerca da capacidade das instituições religiosas hegemônicas, e de seus seguidores, de atuarem de acordo com padrões de reciprocidade.

Sendo assim, sua abordagem pondera o estatuto da neutralidade do Estado quando entendida somente como ausência de intervenção em um ambiente de pluralismo moral. Mesmo considerando este um valor central 
da laicidade, a socióloga canadense avalia cenários em que a neutralidade se transforma potencialmente em dispositivo de normatização dos valores religiosos hegemônicos, ao provocar paralisia decisória ou omissão do Estado em conflitos envolvendo intolerância entre grupos com poderes assimétricos. Por isso, em sua perspectiva, o Estado laico e democrático tem como obrigação proteger os grupos minoritários da pressão exercida pelos grupos majoritários, que frequentemente mobilizam seus recursos para sedimentar como "naturais" ou legítimos os seus valores na esfera pública (Milot, 2008; 2010; Nussbaum, 2010; 2011).

De todo modo, em síntese, a laicidade aberta compreende que o Estado laico deve favorecer o pluralismo moral e religioso, protegendo igualmente todas as manifestações de crença e consciência. Logo, é função do Estado laico reconhecer que não possui competência moral para aplicar uma lei que priorize a legitimidade de uma concepção moral em detrimento de outras, por exemplo, com relação à expressão da sexualidade ou ao aborto.

Por sua vez, no paradigma fechado, a laicidade é elaborada enquanto dispositivo de regimento da esfera pública, o qual estabelece um parâmetro de convivência comum, sem concessões ou privilégios. Neste caso, excluindo do espaço público e dos assuntos políticos concepções particulares de bem, sobretudo de matriz religiosa. Neste enquadramento, a função da laicidade do Estado é organizar o pluralismo moral em torno de uma unidade social construída por meio de valores universais compartilhados (Bovero, 2013; Blancarte, 2008).

Para o filosofo francês Henri Peña-Ruiz (2001; 2009) três princípios indissociáveis constituem o fundamento destes valores: a liberdade de consciência ${ }^{4}$, a igualdade de direitos de ateus, agnósticos e crentes e a promoção de uma lei comum. A proteção institucional destes princípios possibilita a configuração de um espaço público justo, em que todas as crenças têm mesmo valor e estão subordinadas a uma moral pública plenamente independente dos particularismos. Sendo assim, a integração ${ }^{4} \mathrm{~A}$ liberdade religiosa é compreendida como um caso particular de liberdade de consciência. 
da comunidade política está estruturada na adoção de uma legislação cujas regras são uniformes.

A neutralidade e imparcialidade do Estado desempenham, nesta acepção, o papel fundamental de deslegitimar a influência exercida pelos pressupostos religiosos (ou particulares) em matérias de interesse público. Nesta atribuição da dimensão institucional reside um ideal normativo, que consiste na emancipação das instituições políticas e da sociedade de toda tutela religiosa, cujo provável resultado é a construção de uma razão pública e de uma liberdade de consciência efetivamente livre e alicerçada por preceitos seculares (Peña-Ruiz, 2001; 2010; Bovero, 2013).

A ênfase na circunscrição de importância das religiões no espaço da esfera privada é um dos principais eixos nas críticas atribuídas por teóricos e teóricas da laicidade aberta ao paradigma fechado, recorrentemente definido como hostil à relevância da religião na composição da organização político-social. Contudo, é necessário sinalizar que a ideia de laicidade fechada não deve ser compreendida simplesmente enquanto princípio intolerante e/ou antirreligioso, pois são aspectos primordiais nessa abordagem a inviolabilidade do direito ao exercício da fé e o estabelecimento da liberdade de culto das comunidades devocionais. Do mesmo modo, a tolerância se constitui em uma virtude cívica, a qual estabelece o respeito entre crenças e convicções com modos dessemelhantes de entender a vida (Peña-Ruiz, 2001; Poulat, 2012; Ugarte, 2013; Blancarte, 2004).

Por seu turno, convém mencionar que a oposição do paradigma fechado ao conceito de laicidade do Estado construído pelo comunistarismo e multiculturalismo se dirige, por um lado, à avaliação acerca da política de tolerância, já que em muitas elaborações há certa inclinação a institucionalizar a desigualdade entre aquele que tolera, em posição de privilégio, e aquele que é tolerado. Por outro lado, se deve à supervalorização da diversidade social e religiosa, a ponto de dissolver a unidade pública que torna equânime as múltiplas convicções. Por último, ao fato de essas correntes teóricas se apoiarem em uma visão acolhedora e fraternal da relação entre os grupos identitários e entre a religião e a política, renunciando evidências que 
demonstram a relevante mobilização das crenças majoritárias para impor sua visão de mundo às pessoas que não partilham dela (Peña-Ruiz, 2002; Poulat, 2012).

A proposta que compõe o paradigma fechado é extremamente relevante para o debate conceitual e concreto sobre o desenvolvimento da laicidade no mundo contemporâneo, especialmente por recuperar teoricamente sua dimensão emancipatória. Agora, é necessário ponderar que parte dessas premissas se propõe a refleti-la a partir de um modelo ideal, nomeadamente alicerçado pela experiência francesa. Roberto Blancarte, sociólogo mexicano, tem apresentado panoramas originais para pensar a laicidade, bem como realizado críticas aos teóricos franceses, por entender que suas abordagens provocam séria confusão no entendimento da laicidade, em virtude de estes tomarem como referência a experiência de seu país e associá-la ao processo sociopolítico geral que envolve o fenômeno.

Em sua perspectiva, a laicidade também se configura propriamente como regime social de convivência baseado na liberdade de consciência, cujas instituições públicas estão legitimadas principalmente pela soberania popular e não por elementos religiosos. No entanto, o grau de autonomia e a fonte de legitimação do poder político são os fatores fundamentais para entender a especificidade dos regimes laicos nas sociedades modernas (Blancarte, 2000; 2008). A partir disso, a aplicação de fórmulas institucionais é incapaz por si só de assegurar seu desenvolvimento. Essa conclusão é derivada da acepção de que a transição da fonte de legitimação do sistema político de formas sagradas para democráticas é resultado de um processo, cujo envolvimento das forças políticas e sociais é singular na construção da laicidade, assim como da democracia. Logo, as modificações em seu desenho estão abertas e, assim, é impossível sustentar que por razões intrínsecas (como os valores constitutivos da sociedade política) um regime será definitivamente laico, muito menos afirmar que devido à ausência de certas condições estruturais determinados países são suscetíveis a fracassar em engendrar seu desenvolvimento (Blancarte, 2000; 2004; 2008; 2015). 


\section{Considerações finais}

Neste texto, procuramos desenvolver um parâmetro conceitual sobre a laicidade do Estado, cuja finalidade foi demonstrar que sua implementação e desenvolvimento são capazes de promover a regulação e a garantia da legitimidade das diferentes visões de mundo. Sendo assim, o Estado deve se tornar o ente independente capaz de preservar a diversidade de ideias, crenças e a descrença. Não obstante, isso depende de estruturas e arranjos jurídicos, políticos e sociais que o legitime e lhe permita tomar medidas que obstruam interferências externas, sobretudo de crenças que pretendem universalizar suas concepções no espaço público. Portanto, em cada Estado, a laicidade apresenta configurações peculiares, que se modificam de acordo com as circunstâncias históricas de elaboração ou transformação dessas estruturas e arranjos que lhe servem de suporte.

Nosso propósito ao analisar os dois modelos teóricos sobre a laicidade não foi apontar qual o mais adequado, mas sim apresentar suas respectivas singularidades, assim como buscar uma síntese. É possível perceber que há pontos de convergência entre as propostas mais abertas à ingerência religiosa na esfera pública e aquelas que compreendem que sua participação deve estar restrita à esfera privada. O denominador comum entre estas matrizes teóricas se concentra em dois aspectos. O primeiro deles consiste na existência de um vínculo intrínseco entre democracia e laicidade. De fato, é plausível considerar que regimes autoritários ou sistemas de governos com outros modos de organização do poder político, como as monarquias constitucionais, possam executar arranjos institucionais laicos (Blancarte, 2008). No caso da democracia, é uma condição sine qua non assegurar os pilares da laicidade, ou seja, inexiste a probabilidade de um regime ser plenamente democrático sem garantir a manifestação e a igualdade entre as concepções morais (religiosas ou seculares) adotadas pelas pessoas. Parece válido salientar novamente que há exceções a esta norma, por exemplo, em situações que provoquem danos a terceiros (abusos físicos ou injúria). Contudo, em uma democracia, nenhuma concepção de bem deve ser 
proibida ou marginalizada simplesmente por causar aflição moral a terceiros, tais como em virtude da realização de práticas ou atos divergentes a um estilo de vida específico. O segundo aspecto, relacionado ao anterior, está assentado no consenso de que o sistema político não possui atribuição para adotar políticas que venham a impor uma visão de mundo à sociedade, legitimando uma concepção moral em detrimento das outras.

\section{Agradecimentos}

Agradeço imensamente a leitura atenta e sugestões realizadas pelas professoras Flávia Biroli, minha orientadora, Maria José Rosado-Nunes, Danusa Marques, Susana Rostagnol e aos/ às pareceristas anônimos/as da Revista Sociologias. Agradeço também às agências CAPES, CNPQ e FAPDF, que possibilitaram de diferentes formas a realização desta investigação.

Luis Gustavo Teixeira da Silva é Doutor em Ciência Política pela Universidade de Brasília $(U n B)$ e Professor do Departamento de Sociologia e Política da Universidade Federal de Pelotas (UFPel).

$\supseteqq$ gustavoteixeira2519@gmail.com.

\section{Referências}

1. BERGER, Peter; ZIJDERVELD, Andrew. Em favor da dúvida: como ter convicções sem se tornar um fanático. Rio de Janeiro: Editora Elsevier, 2012.

2. BLANCARTE, Roberto. ¿Por qué la religión "regresó" a la esfera pública en un mundo secularizado? Estudios Sociológicos, v. XXXIII, n. 99, p. 659-73, set./dez. 2015.

3. BLANCARTE, Roberto. Religión y sociología, cuatro décadas alrededor del concepto de secularización. Estudios Sociológicos, v. XXX, n. extra., p. 59-81, 2012.

4. BLANCARTE, Roberto. "El porqué de un Estado laico". In: Los retos de la laicidad y la secularización en el mundo contemporáneo. Cidade do México: El Colegio de México, 2008, p. 27-46.

5. BLANCARTE, Roberto. Definir la laicidad (desde una perspectiva mexicana). Revista RIFP, n. 24, p. 15-27, 2004.

6. BLANCARTE, Roberto. Laicidad y valores en un Estado democrático. Cidade do México: El Colegio de México-Secretaría de Gobernación, 2000. 
7. BOVERO, Michelangelo. Laicidad. Un concepto para la teoría moral, jurídica y política. In: UGARTE, Pedro; CAPDEVILLE, Pauline (Orgs.). Para entender y pensar la laicidad. Colección Jorge Carpizo. Vol. I. Cidade do México: Ed. UNAM, 2013, p. 249-70.

8. CASANOVA, José. The secular, secularizations, secularisms. In: CALHOUN, Craig et al. Rethinking secularism. Oxford: Oxford University Press, 2012, p. 31-53.

9. CASANOVA, José. Public religions in the modern world. Chicago: Chicago University Press, 1994.

10. GALEANA, Patrícia. El pensamiento laico de Benito Juárez. In: UGARTE, Pedro; CAPDEVILLE, Pauline (Orgs.). Para entender y pensar la laicidad. Colección Jorge Carpizo. Vol. I. Cidade do México: Ed. UNAM, 2013, p. 67-92.

11. GUIGOU, Nicolás. Religião e política no Uruguai. In: ORO, Ari (Org.). Religião e política no Cone Sul: Argentina, Brasil e Uruguai. São Paulo: Attar Editorial, 2011, p. 157-208.

12. IGLESIAS, Pablo. ¿Capitalismo y neoliberalismo: el nuevo clericalismo? In: PEÑA-RUIZ, Henri; IGLESIA, César T. (Orgs.). La antología laica: 66 textos comentados para comprender el laicismo. Salamanca: Ed. Universidad de Salamanca, 2009, p. 183-7.

13. KEPEL, Gilles. A revancha de Deus: cristãos, judeus e muçulmanos na reconquista do mundo. São Paulo: Editora Siciliano, 1992.

14. KYMLICKA, Will. Multicultural citizenship. A liberal theory of minority rights. Oxford: Oxford University Press, 1995.

15. MACLURE, Jocelyn; TAYLOR, Charles. Laicidad y libertad de conciencia. Madrid: Alianza Editorial, 2011.

16. MARIANO, Ricardo. Expansão e ativismo político de grupos evangélicos conservadores. Secularização e pluralismo em debate. Civitas: Revista de Ciências Sociais, v. 16, p. 710-28, 2016. DOI: http://dx.doi.org/10.15448/19847289.2011.2.9647

17. MARIANO, Ricardo. Laicidade à brasileira: católicos, protestantes e laicos em disputa na esfera pública. Civitas: Revista de Ciências Sociais, v. 11, n. 2 p. 23858, maio/ago. 2011

18. MILOT, Micheline. Laicidad y respeto a la diversidad cultural. In: RODRÍGUEZ, Eliza et al. El estado laico, democracia y libertades. Cidade do México: Ed. Cámara de Diputados de México, 2010, p. 45-55.

19. MILOT, Micheline. La laicidad. Madrid: Editorial CCS, 2009.

20. MILOT, Micheline. La laicización y la secularización en Canadá: dos procesos distintos. In: BLANCARTE, Roberto (Org.). Los retos de la laicidad y la secularización en el mundo contemporáneo. Cidade do México: El Colegio de México, 2008, p. 339-68. 
21. NUSSBAUM, Martha. Libertad de conciencia: el ataque a la igualdad de respeto. Madrid: Ed. Katz, 2011.

22. NUSSBAUM, Martha. Libertad de conciencia: contra los fanatismos. Barcelona: Ed. Tusquets, 2010.

23. PEÑA-RUIZ, Henri. Lecciones de la laicidad francesa. La laicidad como principio fundamental de la libertad y de igualdad. In: RODRÍGUEZ, Eliza et al. El estado laico, democracia y libertades. Cidade do México: Ed. Cámara de Diputados de México, 2010, p. 31-41.

24. PEÑA-RUIZ, Henri. Introducción - Antología Laica. In: PEÑA-RUIZ, Henri; IGLESIA, César Tejedor (Orgs.). La Antología laica: 66 textos comentados para comprender el laicismo. Salamanca: Ed. Universidad de Salamanca, 2009, p. 3561.

25. PEÑA-RUIZ, Henri. La laicidad. Madrid: Siglo XXI Ediciones, 2002.

26. PEÑA-RUIZ, Henri. La emancipación laica. Filosofía de la laicidad. Madrid: Laberinto, 2001.

27. POULAT, Émile. Nuestra laicidad pública. Cidade do México: Fondo de Cultura Económica, 2012.

28. SELEME, Hugo. La condena católica al liberalismo y a la democracia. In: UGARTE, Pedro; CAPDEVILLE, Pauline (Orgs.). Para entender y pensar la laicidad. Colección Jorge Carpizo. Vol. I. Cidade do México: Ed. UNAM, 2013, p. 465-95.

29. SILVA, Luis G. T. Laicidade do Estado no Uruguai: considerações a partir do debate parlamentar sobre o aborto (1985-2016). Religião e Sociedade, v. 38, n. 2, p. 53-84, 2018a. DOI: http://dx.doi.org/10.1590/0100-85872018v38n2cap02.

30. SILVA, Luis G. T. Sobre corpos, crucifixos e liberdades: a laicidade do Estado analisada a partir do debate legislativo sobre o aborto no Brasil e no Uruguai (1985-2016). 283 f., il. Tese (Doutorado em Ciência Política), Universidade de Brasília, Brasília, 2018b.

31. SILVA, Luis G. T. Religião e Política no Brasil. Latinoamerica. Revista de Estudios Latinoamericanos, Cidade do México, Univ. Nacional Autónoma de México (UNAM), v. 64, p. 223-56, 2017. DOI: http://dx.doi.org/10.22201/ cialc.24486914e.2017.64.56799.

32. TAYLOR, Charles. Why we need a radical redefinition of secularism. In: MENDIETA, Eduardo; VAN ANTWERPEN, Jonathan (Orgs.). The power of religion in the public sphere. Nova York: Columbia University Press, 2013, p. 34-59.

33. TAYLOR, Charles. Western secularism. In: CALHOUN, Craig et al. Rethinking secularism. Oxford: Oxford University Press, 2012, p. 31-53.

34. TAYLOR, Charles. A secular age. Cambridge: Harvard University Press, 2007.

35. TSCHANNEN, Olivier. The secularization paradigm; a systematization. Journal for the Scientific Study of Religion, v. 30, n. 4, p. 395-415, 1991. 
36. UGARTE, Pedro. Un archipiélago de laicidades. In: UGARTE, Pedro; CAPDEVILLE, Pauline (Orgs.). Para entender y pensar la laicidad. Colección Jorge Carpizo. Vol. I. Cidade do México: Ed. UNAM, 2013, p. 31-65.

37. WALZER, Michel. Da tolerância. São Paulo: Martins Fontes, 1999.

38. ZEPEDA, José de J. Secularização ou ressacralização? O debate sociológico contemporâneo sobre a teoria da secularização. Revissta Brasileira de Ciências Sociais, v. 25, n. 73, p. 129-41, 2010. DOl: http://dx.doi.org/10.1590/S010269092010000200008

Recebido: 12 ago. 2018

Aceito: 22 jan. 2019 